\title{
Computer Based Thermodynamic Properties of Ammonia-Water Mixture for the Analysis of Power and Refrigeration Cycles
}

\author{
K. Sadhukhan, A. K. Chowdhuri and B. K. Mandal \\ Department of Mechanical Engineering \\ Bengal Engineering and Science University, Shibpur, \\ Howrah -7111103, India \\ Corresponding Author: - B. K. Mandal, e-mail: bkm375@yahoo.co.in
}

\begin{abstract}
The thermodynamic analysis and optimization of combined power and refrigeration cycle as well as the improved vapour absorption refrigeration system necessitate the development of computer based thermodynamic properties of ammonia-water mixture. In this work, a computer code has been developed for the thermodynamic properties of ammonia water mixture for different pressures, temperatures and ammonia mass fraction concentration. This has been achieved by using some exact thermodynamic relations and some correlations available in the literature. The computed results have been compared with the published experimental data and the agreement is found to be of good accuracy. The errors in the computed results for different thermodynamic properties are slightly more at comparatively high pressure and temperature. The maximum error is found to be with saturated liquid mixture entropy and its value is also less then $3.8 \%$ even at a high pressure of $3.447 \mathrm{MPa}$.
\end{abstract}

Keywords: Ammonia water mixture; enthalpy; entropy; Gibbs free energy; mass fraction; thermodynamic properties.

\section{INTRODUCTION}

The use of ammonia water mixture as refrigerant is in vogue for industrial vapour absorption refrigeration systems. The simulation and optimization of absorption refrigeration systems require the availability of simple and efficient mathematical methods for the determination of the thermodynamic properties of the working fluid (ammonia water mixture). The graphical methods of Merkel and Bošnjaković (Merkel \& Bošnjaković, 1929) and Niebergall (Niebergall, 1959) are suitable for the analysis of simpler cycles, but they get cumbersome and difficult to use for calculations for more complex cycles, such as GAX (Generator-Absorber heat exchange), where the diluted solution is also used as heat transfer fluid between the absorber and the generator and also in power cycles Kalina (Kalina, 1983) showed the use of ammonia water mixture in a thermodynamic cycle (popularly known as Kalina cycle) to obtain power output. The proposition of Kalina cycle had led to significant increase of research work to estimate the properties of ammonia water mixture precisely. Recently, thermodynamic cycles have been developed to generate power and refrigeration effect simultaneously with ammonia water mixture as the working fluid. The importance of the development work done in these new formulations is demonstrated by the adoption of the formulations proposed in Tillner -Roth and Friend (Tillner -Roth \& Friend, 1998) by the International Association for the Properties of Water and Steam (IAPWS, 2001).

\section{LITERATURE REVIEW}

Various studies have been done to determine the thermodynamic properties of ammonia water mixture over a long period of time. Scatchard et al. (Scatchard, Epstein,
Warburton \& Cody, 1947) proposed new values of enthalpy and entropy of ammonia water mixture. Patek and Klomfar (Patek \& Klomfer, 1995) used a set of five equations to determine the vapour liquid equilibrium properties of ammonia water mixture avoiding iterations. Those equations were generated by fitting critically assessed experimental data of Smolen et al. (Smolen, Manley \& Poling, 1991), Sassen et al. (Sassen, Kwartel, van der Kooi \& de Swaan, 1990), Rizvi and Heidemann (Rizvi \& Heidemann, 1987) , Scatchard et al. (Scatchard, Epstein, Warburton \& Cody, 1947), Wilson (Wilson, 1924) and Perman (Perman, 1901). The results were presented in the form of enthalpy-concentration diagrams by Patek and Klomfar (Patek \& Klomfer, 1995). Although the equations used by them are of completely empirical nature, the property values obtained from these equations are quite acceptable for industrial use for pressure below $3 \mathrm{MPa}$. Abovsky (Abovsky, 1996) used the thermodynamic perturbation theory to determine the properties of the pure substance and their mixture in the temperature range of 200 - $640 \mathrm{~K}$ and pressure range of $0.02-23 \mathrm{MPa}$. He also studied the deviations from one-fluid approximation of the mixture considering the effects of mixing on enthalpy and volume. Ibrahim and Klein (Ibrahim \& Klein, 1993) and Xu and Goswami (Xu \& Goswami, 1999) used Gibb's free energy equation to formulate the thermodynamic properties of ammonia water mixture. Weber (Weber, 1999) presented a model to estimate the second and the third virial coefficients of ammonia water mixture. Berhoumi et al. (Barhoumi, Snoussi, Ezzine, Mejbri \& Bellagi, 2004) formulated thermodynamic properties of ammonia-water mixture based on Gibbs free energy and Margules model of the excess free enthalpy. For each pure component in gaseous phase separate virial coefficient type equation of 
state has been considered. Their model was capable of predicting the property values in the three states, namely, subcooled liquid, superheated vapour and liquid-vapour saturation for temperatures from 200 to $500 \mathrm{~K}$ and pressures upto $10 \mathrm{MPa}$. Mejbri and Bellagi (Mejbri \& Bellagi, 2006) compared the thermodynamic properties of ammonia water mixture obtained using three different models. The models were based on Gibbs free enthalpy, the Patel-Teja cubic equation of state and the PC-SAFT equation of state respectively. They also recommended the use of Gibbs free enthalpy model for industrial vapour absorption refrigeration system with moderate temperatures and pressures and PC-SAFT for power cycle calculations where high temperatures and pressures are encountered. ElSayed and Tribus (El-Sayed \& Tribus, 1985) proposed a model to calculate the bubble and dew point properties by correlations without using iterations. Analysis and optimization of ammonia-water mixture based refrigeration or power or combined cycles need the estimation of the mixture properties at various conditions of pressure, temperature and ammonia mass fraction repeatedly. Hence, there is a need of a code for the thermodynamic properties of ammonia water mixture, which could be used as a subroutine in the analysis of the different cycles mentioned above. This paper aims at determining the thermodynamic properties of ammonia water mixture for a wide range of conditions of pressure and temperature with the help of a computer program.

\section{MATHEMATICAL FORMULATION}

\subsection{Gibbs free energy}

The mathematical formulation of the thermodynamic properties of ammonia water mixture is based on some exact thermodynamic relations and a few empirical corelations found in the literature. The formulation is primarily based on Gibbs free energy method. The empirical correlations have been taken from $\mathrm{Xu}$ and Goswami (Xu \& Goswami, 1999) and Taleb et al. (Taleb, Feidt \& Lottin, 2003). The Gibbs free energy of a pure substance can be derived from known relations for volume and heat capacity as a function of temperature and pressure. The Gibbs free energy for a pure substance in the integral form is given by

$$
G=h_{o}-T s_{o}+\int_{T_{o}}^{T} C_{p} d T+\int_{P_{o}}^{P} v d P-T \int_{T_{0}}^{T}\left(\frac{C_{p}}{T}\right) d T
$$

The correlations for the volume, $v$ and the heat capacity at constant pressure, $C_{p}$, for the liquid and vapour phase of both pure water and pure ammonia have been considered from the work of Ziegler and Trepp (Ziegler \& Trepp, 1984) in the following forms:

$$
\begin{aligned}
& v^{L}=a_{1}+a_{2} P+a_{3} T+a_{4} T^{2} \\
& v^{g}=\frac{R T}{P}+C_{1}+\frac{C_{2}}{T^{3}}+\frac{C_{3}}{T^{11}}+\frac{C^{4} P^{2}}{T^{11}} \\
& C_{P}^{L}=b_{1}+b_{2} T+b_{3} T^{2}
\end{aligned}
$$

$C_{P}^{g}=d_{1}+d_{2} T+d_{3} T^{2}-\int_{0}^{P_{0}}\left(\frac{\partial^{2} v}{\partial T^{2}}\right)_{P} d P$

The values of $v$ and $C_{P}$ for liquid state obtained from Eq.(2) and Eq.(3) are substituted in Eq. (1) to get for Gibbs free energy for liquid state. For generalization the Gibbs free energy at reduced state is calculated and written for liquid phase as

$$
\begin{aligned}
& G_{r}^{L}=h_{r, o}^{L}-T_{r} s_{r, o}^{L}+B_{1}\left(T_{r}-T_{r, o}\right)+\left(\frac{B_{2}}{2}\right)\left(T_{r}^{2}-T_{r, o}^{2}\right)+ \\
& \left(\frac{B_{3}}{3}\right)\left(T_{r}^{3}-T_{r, o}^{3}\right)-B_{1} T_{r} \ln \left(\frac{T_{r}}{T_{r, o}}\right)-B_{2} T_{r}\left(T_{r}-T_{r, o}\right)- \\
& \left(\frac{B_{3}}{2}\right) T_{r}\left(T_{r}^{2}-T_{r, o}^{2}\right)+\left(A_{1}+A_{3} T_{r}+A_{4} T_{r}^{2}\right)\left(P_{r}-P_{r, o}\right)+ \\
& \left(\frac{A_{2}}{2}\right)\left(P_{r}^{2}-P_{r, o}^{2}\right)
\end{aligned}
$$

The reduced thermodynamic properties are defined as

$G_{r}=\frac{G}{R T_{B}}, T_{r}=\frac{T}{T_{B}}, P_{r}=\frac{P}{P_{B}}, s_{r}=\frac{s}{R}$ and

$v_{r}=\frac{v P_{B}}{R T_{B}}$. The values of the constants $R, T_{B}$ and $P_{B}$ are $8.314 \mathrm{~kJ} / \mathrm{kmol}-\mathrm{K}, 100 \mathrm{~K}$ and $1 \mathrm{MPa}$ respectively.

In a similar way, the Gibbs free energy for gaseous phase at reduced state is obtained as

$$
\begin{aligned}
G_{r}^{g}= & h_{r, o}^{g}-T_{r} s_{r, o}^{g}+D_{1}\left(T_{r}-T_{r, o}\right)+\left(\frac{D_{2}}{2}\right)\left(T_{r}^{2}-T_{r, o}^{2}\right)+ \\
& \left(\frac{D_{3}}{3}\right)\left(T_{r}^{3}-T_{r, o}^{3}\right)-D_{1} T_{r} \ln \left(\frac{T_{r}}{T_{r, o}}\right)-D_{2} T_{r}\left(T_{r}-T_{r, o}\right)- \\
& \left(\frac{D_{3}}{2}\right)\left(T_{r}^{2}-T_{r, o}^{2}\right)+T_{r} \ln \left(\frac{P_{r}}{P_{r, o}}\right)+C_{1}\left(P_{r}-P_{r, o}\right)+ \\
& C_{2}\left(\frac{P_{r}}{T_{r}^{3}}-4 \frac{P_{r, o}}{T_{r, o}^{3}}+3 P_{r, o} \frac{T_{r}}{T_{r, o}^{4}}\right)+ \\
& C_{3}\left(\frac{P_{r}}{T_{r}^{11}}-12 \frac{P_{r, o}}{T_{r, o}^{11}}+11 P_{r, o} \frac{T_{r}}{T_{r, o}^{12}}\right)+ \\
& \left(\frac{C_{4}}{3}\right)\left(\frac{P_{r}^{3}}{T_{r}^{11}}-12 \frac{P_{r, o}^{3}}{T_{r, o}^{11}}+11 P_{r, o}^{3} \frac{T_{r}}{T_{r, o}^{12}}\right)
\end{aligned}
$$

The values of the different coefficients $\left(A_{i}, B_{i}, C_{i}, D_{i}\right)$ used in Eqs. (6-7) are presented in Table I.

The molar specific enthalpy $(h)$, entropy $(s)$ and volume $(v)$ of a pure component can be related to Gibbs free energy, in terms of reduced variables as

$$
\begin{aligned}
& h=-R T_{B} T_{r}^{2}\left[\frac{\partial}{\partial T_{r}}\left(\frac{G_{r}}{T_{r}}\right)\right]_{P_{r}} \\
& s=-R\left[\frac{\partial G_{r}}{\partial T_{r}}\right]_{P_{r}}
\end{aligned}
$$


Table 1: Coefficients and constants of Eqs. (6) and (7).

\begin{tabular}{ccc}
\hline Coefficients & Ammonia & Water \\
\hline$A_{1}$ & $3.971423 \times 10^{-2}$ & $2.748796 \times 10^{-2}$ \\
$A_{2}$ & $-1.790557 \times 10^{-5}$ & $-1.016665 \times 10^{-5}$ \\
$A_{3}$ & $-1.308905 \times 10^{-2}$ & $-4.452025 \times 10^{-3}$ \\
$A_{4}$ & $3.752836 \times 10^{-3}$ & $8.389246 \times 10^{-4}$ \\
$B_{1}$ & $1.634519 \times 10^{1}$ & $1.214557 \times 10^{1}$ \\
$B_{2}$ & -6.508119 & -1.898065 \\
$B_{3}$ & 1.448937 & $2.911966 \times 10^{-2}$ \\
$C_{1}$ & $-1.049377 \times 10^{-2}$ & $2.136131 \times 10^{-2}$ \\
$C_{2}$ & -8.288224 & $-.169291 \times 10^{1}$ \\
$C_{3}$ & $-.647257 \times 10^{2}$ & $-.634611 \times 10^{4}$ \\
$C_{4}$ & $-3.045352 \times 10^{3}$ & 0.0 \\
$D_{1}$ & 3.673647 & 4.019170 \\
$D_{2}$ & $9.989629 \times 10^{-2}$ & $-5.175550 \times 10^{-2}$ \\
$D_{3}$ & $3.617622 \times 10^{-2}$ & $1.951939 \times 10^{-2}$ \\
$h_{r, o}^{L}$ & 4.878573 & 21.821141 \\
$h_{r, o}^{g}$ & 26.468873 & 60.965058 \\
$s_{r, o}^{L}$ & 1.644773 & 5.733498 \\
$s_{r, o}^{g}$ & 8.339026 & 13.453430 \\
$T_{r, o}$ & 3.2252 & 5.0705 \\
$P_{r, o}$ & 2.000 & 3.000 \\
& & \\
& & \\
\hline
\end{tabular}

and

$v=\frac{R T_{B}}{P_{B}}\left[\frac{\partial G_{r}}{\partial P_{r}}\right]_{T_{r}}$

\subsection{Ammonia water mixture}

The liquid mixture of ammonia and water deviates from ideal solution mixture. This deviation of liquid mixture from ideal solution behavior is taken into account through Gibbs excess energy as suggested by Ziegler and Trepp (Ziegler \& Trepp, 1984). Hence the Gibbs free energy of a liquid mixture of ammonia-water is obtained by adding the Gibbs excess energy with the Gibbs energy of the ideal solution mixture.

The Gibbs excess energy for a liquid mixture is calculated from the following empirical relations as proposed by Xu and Goswami (Xu \& Goswami, 1999; Xu \& Goswami, 2002).

$G_{r}^{E}=\left[F_{1}+F_{2}(2 x-1)+F_{3}(2 x-1)^{2}\right](1-x) x$

where,

$$
\begin{aligned}
& F_{1}=E_{1}+E_{2} P_{r}+\left(E_{3}+E_{4} P_{r}\right) T_{r}+\frac{E_{5}}{T_{r}}+\frac{E_{6}}{T_{r}^{2}} \\
& F_{2}=E_{7}+E_{8} P_{r}+\left(E_{9}+E_{10} P_{r}\right) T_{r}+\frac{E_{11}}{T_{r}}+\frac{E_{12}}{T_{r}^{2}} \\
& F_{3}=E_{13}+E_{14} P_{r}+\frac{E_{15}}{T_{r}}+\frac{E_{16}}{T_{r}^{2}}
\end{aligned}
$$

where $x$ is the ammonia mass fraction.

The original equation proposed by $\mathrm{Xu}$ and Goswami does not generate sufficiently correct results. Hence it has been modified as proposed by Taleb et al. (Taleb, Feidt \& Lottin, 2003). The values of the coefficients used in empirical relations of Eqs. (12-14) have been taken from Taleb et al. (Taleb, Feidt \& Lottin, 2003) and also listed in Table II. The excess specific enthalpy, entropy and volume for the liquid mixture are calculated as

$h^{E}=-R T_{B} T_{r}^{2}\left[\frac{\partial}{\partial T_{r}}\left(\frac{G_{r}^{E}}{T_{r}}\right)\right]_{P_{r}, x}$

$s^{E}=-R\left[\frac{\partial G_{r}^{E}}{\partial T_{r}}\right]_{P_{r}, x}$

$v^{E}=\frac{R T_{B}}{P_{B}}\left[\frac{\partial G_{r}^{E}}{\partial P_{r}}\right]_{T_{r} . x}$

Therefore, the specific enthalpy, entropy and volume for the liquid mixture are given by

$h_{m}^{L}=x h_{a}^{L}+(1-x) h_{w}^{L}+h^{E}$

$s_{m}^{L}=x s_{a}^{L}+(1-x) s_{w}^{L}+s^{E}+s^{m i x}$

$v_{m}^{L}=x v_{a}^{L}+(1-x) v_{w}^{L}+v^{E}$

where

$s^{m i x}=-R[x \ln (x)+(1-x) \ln (1-x)]$

TABLE II: Coefficients of Eqs. (12), (13) and (14).

\begin{tabular}{lcll}
\hline$E_{1}$ & -41.733398 & $E_{9}$ & 0.387983 \\
$E_{2}$ & 0.02414 & $E_{10}$ & 0.004772 \\
$E_{3}$ & 6.702285 & $E_{11}$ & -4.648107 \\
$E_{4}$ & -0.011475 & $E_{12}$ & 0.836376 \\
$E_{5}$ & 63.608967 & $E_{13}$ & -3.553627 \\
$E_{6}$ & -62.490768 & $E_{14}$ & 0.000904 \\
$E_{7}$ & 1.761064 & $E_{15}$ & 24.361723 \\
$E_{8}$ & 0.008626 & $E_{16}$ & -20.736547 \\
\hline
\end{tabular}

As the ammonia water vapour mixtures nearly forms an ideal solution, the Gibbs excess energy for the vapour mixture is assumed to be zero. The specific enthalpy, entropy and volume for the gaseous mixtures are given by 
$h_{m}^{g}=y h_{a}^{g}+(1-y) h_{w}^{g}$

$s_{m}^{g}=y s_{a}^{g}+(1-y) s_{w}^{g}+s^{m i x}$

$v_{m}^{g}=y v_{a}^{g}+(1-y) v_{w}^{g}$

where

$$
s^{m i x}=-R[y \ln (y)+(1-y) \ln (1-y)]
$$

The condensation and boiling processes for a binary mixture normally take place over a range of temperature at a particular pressure. This facilitates the heat transfer process in the sense that the irreversibilities associated with heat transfer to the mixture, when used as working fluid, reduces. The dew point temperature for a binary mixture is defined as the temperature at which the condensation of the mixture begins. Similarly, the temperature of the binary mixture at which boiling starts is called bubble point temperature. Hence for binary mixture of ammonia water, it is essential to determine bubble point and dew point temperatures for evaluating thermodynamic properties of the mixture corresponding to given ammonia mass fraction at a given pressure. The complicated method of calculating the fugacity co-efficient of a component in a mixture to determine the bubble and dew point temperatures is avoided. Rather, an empirical equation is used to determine the bubble point and dew point temperatures.

The bubble point temperature is given by

$T(P, x)=T_{o} \sum_{i} a_{i}(1-x)^{m_{i}}\left[\ln \left(\frac{p_{o}}{p}\right)\right]^{n_{i}}$

and the dew point temperature is given by

$T(P, y)=T_{o} \sum_{i} a_{i}(1-y)^{m_{i} / 4}\left[\ln \left(\frac{p_{o}}{p}\right)\right]^{n_{i}}$

where $T_{o}=100 \mathrm{~K}$ and $P_{o}=2 \mathrm{MPa}$. Values of different coefficients used in the above two equations (26 and 27) have been taken from Patek and Klomfar (Patek \& Klomfer, 1995) and the values are given in Table III and Table IV respectively for ready reference.

\section{RESULTS AND DISCUSSION}

A computer code has been developed based on the above equations to generate the thermodynamic property values for any given condition. The main input parameters are the temperature, pressure and the ammonia mass fraction. Any of the properties like dew point temperature, bubble point temperature, specific enthalpy, specific entropy and specific volume at a particular condition can be obtained from the program. The results obtained from the program are compared with some standard experimental values available in the literature and they seem to comply well with the standard values. Figure 1 shows the variation of dew point and bubble point temperatures with ammonia mass fraction for different pressures. The figure clearly shows that the dew point temperature is higher than the bubble point temperature for a particular pressure and ammonia mass fraction in the mixture. It is also evident that both dew point and bubble point temperatures increase with pressure for a given mass fraction of ammonia. In the two extreme cases of ammonia mass fraction being 0 and 1 , the dew point and bubble point temperatures are the same and are equal to the boiling points of pure water and pure ammonia respectively at that particular pressure. This plot may be used for the determination of dew point and bubble point for different concentrations of ammonia.

Table III: Coefficients of Equation (26).

\begin{tabular}{cccc}
\hline$i$ & $m_{i}$ & $n_{i}$ & $a_{i}$ \\
1 & 0 & 0 & $0.322302 \times 10^{1}$ \\
2 & 0 & 1 & -0.384206 \\
3 & 0 & 2 & $0.460965 \times 10^{-1}$ \\
4 & 0 & 3 & $-0.378945 \times 10^{-2}$ \\
5 & 0 & 4 & $0.135610 \times 10^{-3}$ \\
6 & 1 & 0 & 0.487775 \\
7 & 1 & 1 & -0.120108 \\
8 & 1 & 2 & $0.106154 \times 10^{-1}$ \\
9 & 2 & 3 & $-0.533589 \times 10^{-3}$ \\
10 & 4 & 0 & $0.785041 \times 10^{1}$ \\
11 & 5 & 0 & $-0.115941 \times 10^{2}$ \\
12 & 5 & 1 & $-0.523150 \times 10^{-1}$ \\
13 & 6 & 0 & $0.489596 \times 10^{1}$ \\
14 & 13 & 1 & $0.421059 \times 10^{-1}$ \\
\hline
\end{tabular}

Table IV: Coefficients of Equation (27).

\begin{tabular}{cccc}
\hline$i$ & $m_{i}$ & $n_{i}$ & $a_{i}$ \\
1 & 0 & 0 & $0.324004 \times 10^{1}$ \\
2 & 0 & 1 & -0.395920 \\
3 & 0 & 2 & $0.435624 \times 10^{-1}$ \\
4 & 0 & 3 & $-0.218943 \times 10^{-2}$ \\
5 & 1 & 0 & $-0.143526 \times 10^{1}$ \\
6 & 1 & 1 & $0.105256 \times 10^{1}$ \\
7 & 1 & 2 & $-0.719281 \times 10^{-1}$ \\
8 & 2 & 0 & $0.122362 \times 10^{2}$ \\
9 & 2 & 1 & $-0.224368 \times 10^{1}$ \\
10 & 3 & 0 & $-0.201780 \times 10^{2}$ \\
11 & 3 & 1 & $0.1108344 \times 10^{1}$ \\
12 & 4 & 0 & $0.145399 \times 10^{2}$ \\
13 & 4 & 2 & 0.644312 \\
14 & 5 & 0 & $-0.221246 \times 10^{1}$ \\
15 & 5 & 2 & -0.756266 \\
16 & 6 & 0 & $-0.135529 \times 10^{1}$ \\
17 & 7 & 2 & 0.183541 \\
\hline
\end{tabular}


The computed thermodynamic properties of ammonia water mixture have been compared with pertinent published data available in the literature (Figures 2 to 7 ) and the present formulation provides good degree of agreement between the calculated values and published data.

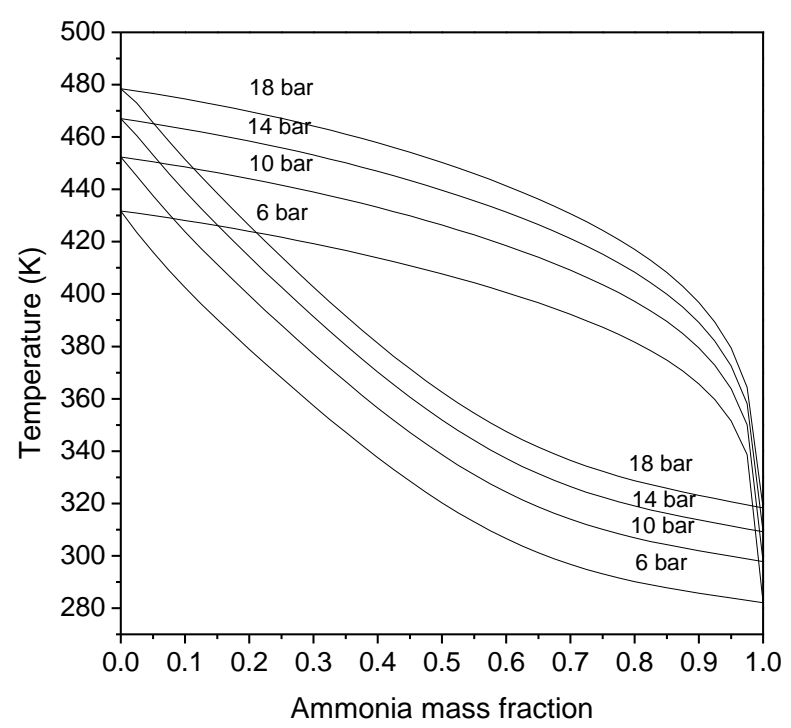

Fig. 1. Variation of dew point and bubble point temperatures with ammonia mass fraction for different pressures.

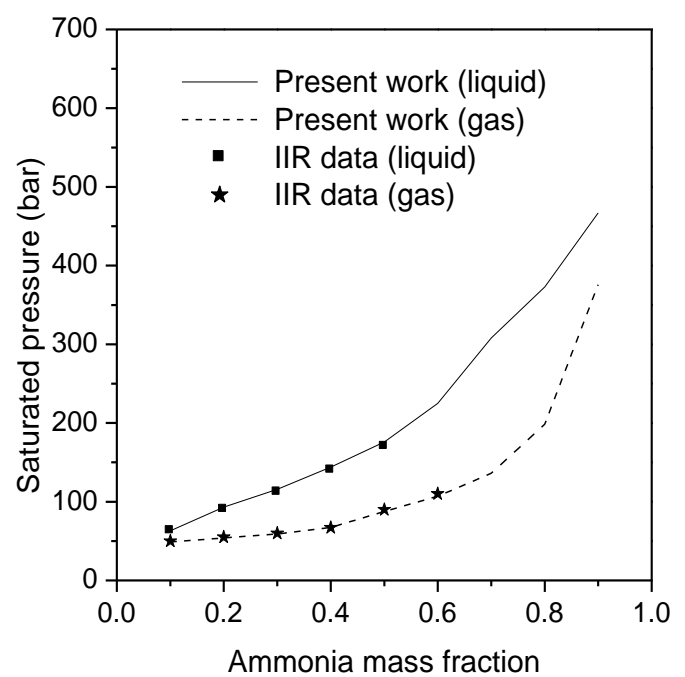

Fig. 2. Saturated pressure vs. ammonia mass fraction at $525.15 \mathrm{~K}$.

Figure 2 shows the variation of saturation pressure with ammonia mass fraction in the mixture at $525.15 \mathrm{~K}$. Although the graph shows that there is a slight deviation of the saturated pressure of the liquid mixture but it is quite acceptable as the temperature is relatively high. The maximum deviation for saturated pressure of gas is limited to only $2.8 \%$. The corresponding error for liquid is slightly higher $(3.5 \%)$. This is an improvement over some of the earlier formulation. The graph clearly shows that as the ammonia mass fraction increases the saturation pressure also increases. Figure 3 shows the variation of saturation pressure with ammonia mass fraction at a relatively lower temperature of $283.15 \mathrm{~K}$. The results obtained from the present formulation are compared with the IIR data (IIR, 1994) and it shows an excellent agreement. The maximum deviations for both liquid and gaseous phases are very less. They are only $1.9 \%$ and $1.6 \%$ respectively.

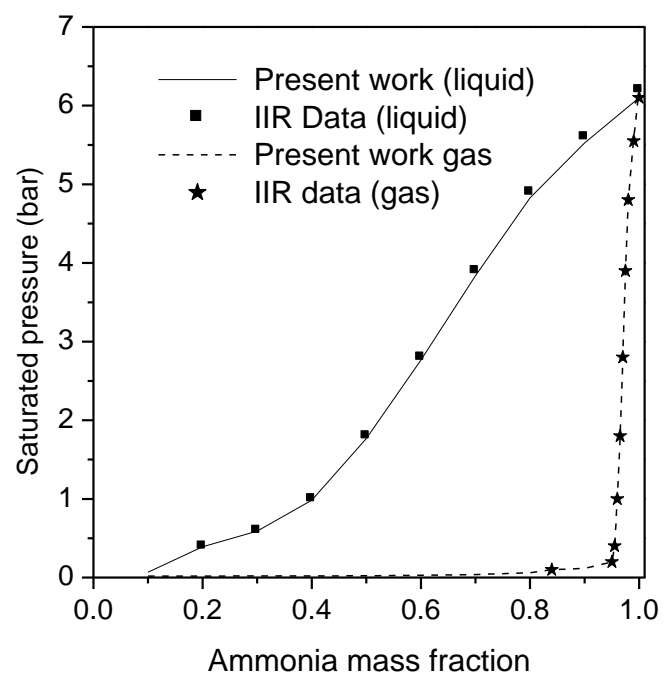

Fig. 3. Saturated pressure vs. ammonia mass fraction at $283.15 \mathrm{~K}$

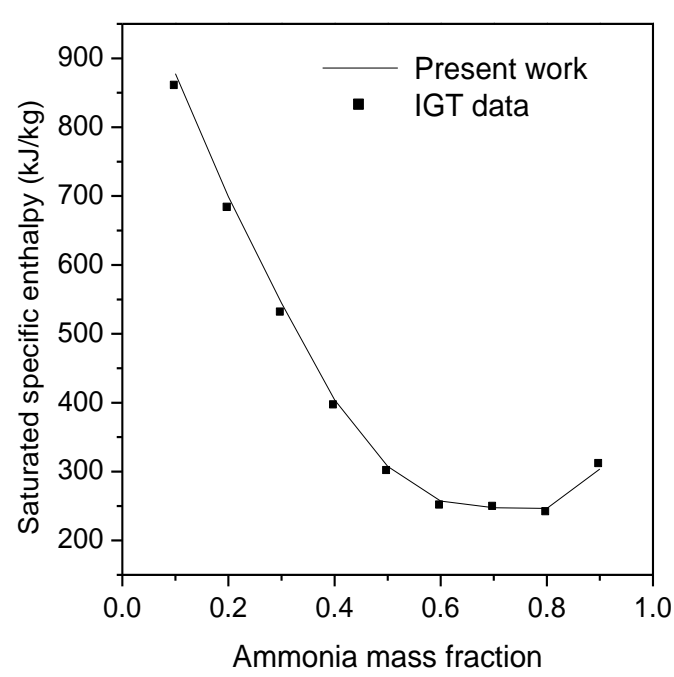

Fig. 4. Specific enthalpy of saturated liquid vs. ammonia mass fraction at 3.447 MPa.

Figure 4 shows the variation of specific enthalpy of saturated liquid with ammonia mass fraction at 3.447 MPa. The results obtained from the program are compared with IGT data (Macriss, Eakine, Ellington \& Huebler, 1964) and it complies well. The maximum error is found to be $2.9 \%$. Considering the high value of pressure, this deviation may be allowed for specific calculation. The graph clearly shows that the specific enthalpy of liquid mixture decreases with ammonia mass fraction up to a certain point. This is due to the fact that the specific enthalpy of water is much higher than that of liquid ammonia and as the mass fraction of water decreases progressively with the increase of mass fraction of ammonia, the specific enthalpy decreases. After a certain point the specific enthalpy increases with ammonia mass fraction. This is because the excess enthalpy due to mixing of the two liquids becomes predominant and 
increases the specific enthalpy of the mixture. Figure 5 shows the variation of specific enthalpy of saturated vapour with mass fraction of ammonia at $1.8 \mathrm{MPa}$. The result, in this case, is also compared with IGT data and it shows excellent agreement. The maximum error is found to be $0.5 \%$, which is negligibly small.

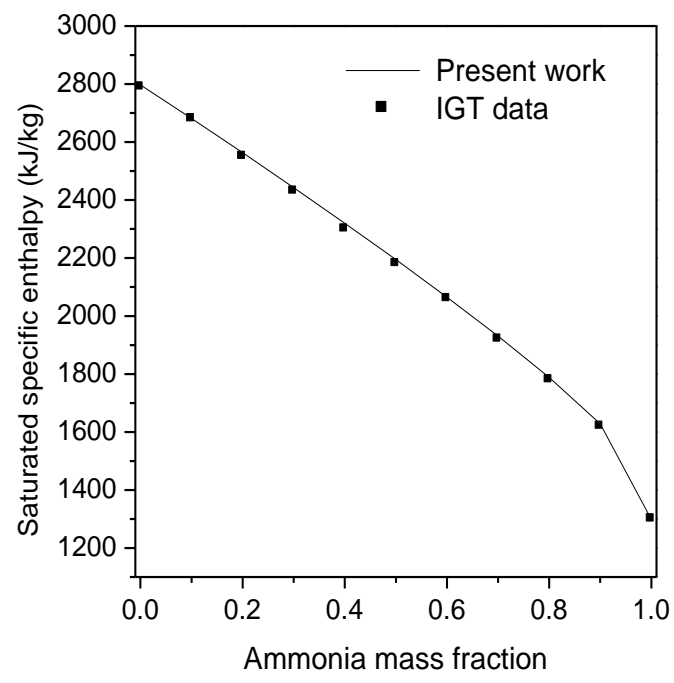

Fig. 5. Specific enthalpy of saturated vapour vs. ammonia mass fraction at 1.8 MPa.

The variation of specific entropy of saturated vapour with ammonia mass fraction at $1.8 \mathrm{MPa}$ has been presented in Fig. 6. The computed values of entropy show a good agreement with the published data of Scatchard et al. (Scatchard, Epstein, Warburton \& Cody, 1947). The deviation is nominal and it is only $1.1 \%$. Figure 7 shows the variation of specific entropy of saturated liquid with ammonia mass fraction at $3.447 \mathrm{MPa}$. The computed values are compared with the published data of Scatchard et al. (Scatchard, Epstein, Warburton \& Cody, 1947). Although the graph shows some variation but it is quite acceptable as the pressure is quite high. Compare to other properties, the deviation of the computed values in this case shows a larger value of $3.8 \%$. Thus the data generated can be used further for the analysis of vapour absorption refrigeration system, Kalina cycle and combined power and refrigeration cycle where thermodynamic property values are often required to be calculated at different conditions of pressure, temperature and ammonia mass fraction. The thermodynamic analysis of the combined cycle needs different property values of the ammonia water mixture repeatedly. Hence the program developed for thermodynamic properties of ammonia water mixture in this work can be used as a subroutine for the analysis of ammonia-water based cycles.

\section{CONCLUSIONS}

This paper has arisen as a first part of a project which aims at developing and analysis of a combined power and refrigeration cycle. In this paper, a property code has been developed to generate thermodynamic properties of ammonia water mixture for both liquid and vapour phase. This code is valid for a wide range of temperature and pressure. The formulation is based on Gibbs free energy and some empirical relations for bubble point and dew point temperatures. The values of various thermodynamic properties obtained from this present formulation are compared with the standard values available in the literature. The matching is excellent upto moderate pressure. At high pressures and temperatures, the computed results show slight variation from the experimental results available in the literature. The maximum error for saturated pressure in the gaseous state is $2.8 \%$ at $525.15 \mathrm{~K}$ and $1.6 \%$ at $283.15 \mathrm{~K}$. The corresponding values for the liquid mixtures at the same two temperatures are $3.5 \%$ and $1.9 \%$ respectively. At $3.447 \mathrm{MPa}$, the maximum deviation for saturated liquid enthalpy is found to be $2.9 \%$. The error for saturated vapour enthalpy of the mixture at $1.8 \mathrm{MPa}$ is less than $0.5 \%$. The deviation of saturated specific entropy of liquid is slightly higher (max. $3.8 \%$ ) at $3.447 \mathrm{MPa}$. However, this deviation for vapour mixture at $1.8 \mathrm{MPa}$ is only $1.1 \%$. Hence, the results generated by this code can be used for the analysis of refrigeration, power and power and refrigeration combined cycles where ammonia water mixture is the working substance.

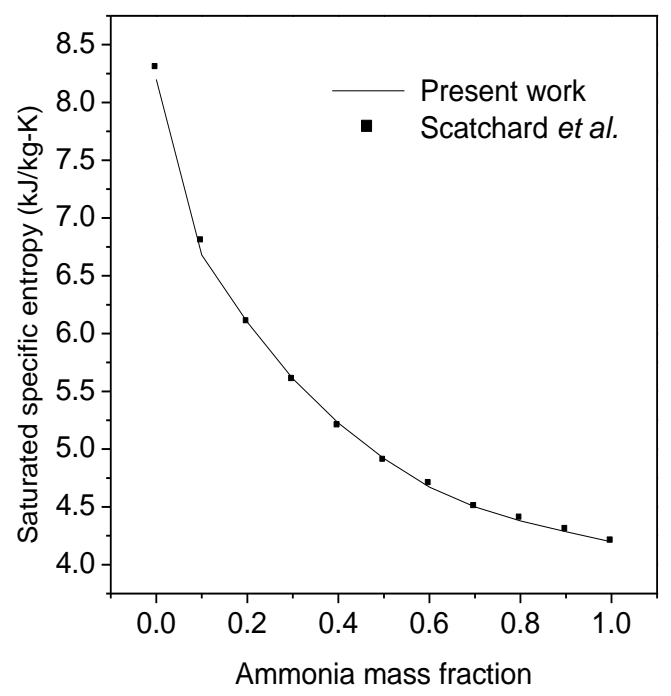

Fig. 6. Specific entropy of saturated vapour vs. ammonia mass fraction at 1.8 MPa.

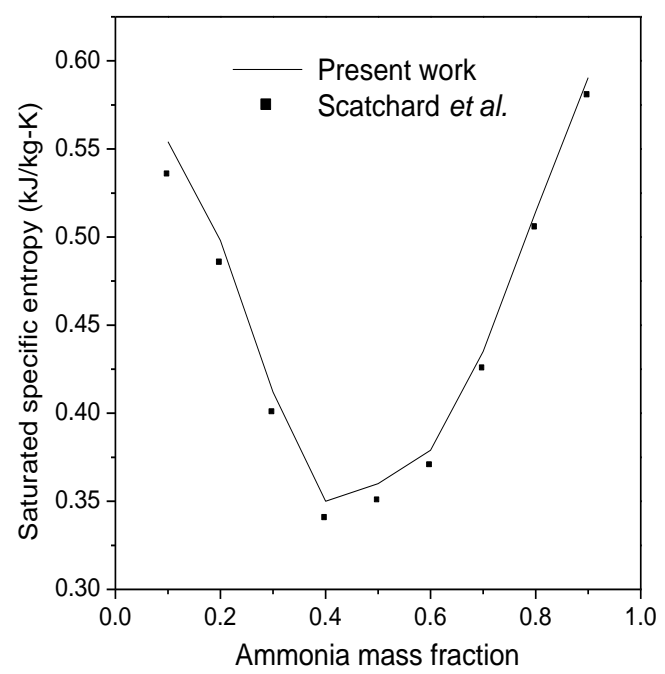

Fig. 7. Specific entropy of saturated liquid vs. ammonia mass fraction at $3.447 \mathrm{MPa}$. 


\section{NOMENCLATURE}

$\begin{array}{ll}C_{p} & \text { Specific heat }(\mathrm{J} / \mathrm{kg}-\mathrm{K}) \\ R & \text { Universal gas constant }(\mathrm{J} / \mathrm{kmol}-\mathrm{K}) \\ G & \text { Gibbs free energy }(\mathrm{J} / \mathrm{kg}) \\ h & \text { specific enthalpy }(\mathrm{J} / \mathrm{kg}) \\ P & \text { pressure }(\mathrm{Pa}) \\ S & \text { specific entropy }(\mathrm{J} / \mathrm{kg}-\mathrm{K}) \\ T & \text { temperature }(\mathrm{K}) \\ v & \text { specific volume }\left(\mathrm{m}^{3} / \mathrm{kg}\right) \\ x & \text { ammonia mole fraction in liquid state } \\ y & \text { ammonia mole fraction in vapour state }\end{array}$

\section{Subscripts}

a ammonia

$m \quad$ mixture

$r \quad$ reduced state

w water

$o \quad$ reference state

\section{Superscripts}

$E \quad$ excess energy

$g \quad$ gas (vapour)

L liquid

\section{REFERENCES}

Abovsky, V. 1996. Thermodynamics of ammonia-water mixture. Fluid Phase Equilibria. Vol. 116: 170-176.

Barhoumi, M. A., Snoussi, N., Ezzine, B., Mejbri, K.H. and Bellagi, A. 2004. Modelling of the thermodynamic properties of the ammonia/water mixture. International Journal of Refrigeration. Vol. 27: 271- 283.

El-Sayed, Y.M. and Tribus, M. 1985. ASME special publication AES 1, New York: ASME, 89.

IAPWS 2001. Guideline on the IAPWS formulation 2001 for the thermodynamic properties of ammonia-water mixtures, Gaithersburg MD, USA.

Ibrahim, O.M. and Klein, S. A. 1993. Thermodynamic properties of ammonia-water mixtures. ASHRAE Transaction. Vol. 99: 1495-1502.

IIR. 1994. Thermodynamic and physical properties of $\mathrm{NH}_{3}$ $\mathrm{H}_{2} \mathrm{O}$, International Institute of Refrigeration, Paris, France.

Kalina, A. I. 1983. Combined cycle and waste-heat recovery power systems based on a novel thermodynamic energy cycle utilizing low-temperature heat for power generation, ASME Paper No. 83-JPGCGT-3.

Macriss, R.A., Eakine, B.E., Ellington, R.T. and Huebler J. 1964. Physical and thermodynamic properties of ammonia-water mixtures. Research Bulletin No. 34. Institute of Gas Technology, Chicago (IL), USA.

Mejbri, K.H. and Bellagi, A. 2006. Modeling of the thermodynamic properties of the water ammonia mixture by three different approaches. International Journal of Refrigeration. Vol. 29:211-218.
Merkel, F. and Bošnjaković , F. 1929. Diagramme und Tabellen Zur Berechnung der AbsorptionsKältemaschinen . Verlag Von Julius Springer, Berlin.

Niebergall, W. 1959. Sorptious- Kä ltemaschinen, Handbuch der Kä ltetechnik, 7, band, Herausgegeben von R. Plank, Springer-Verlag, Berlin.

Patek, J. and Klomfer, J. 1995. Simple functions for fast calculations of selected thermodynamic properties of the ammonia-water system. International Journal of Refrigeration. Vol. 18: 228-234.

Perman, E.P. 1901. Vapour pressure of aqueous ammonia solution, part I. J Chem Soc. (Lond). Vol.79: 718-725.

Rizvi, S.S.H. and Heidemann, R.A. 1987. Vapor-liquid equilibrium in the ammonia-water system. J Chem Eng Data. Vol. 32: 183-191.

Sassen, C.L., Kwartel, R.A.C., van der Kooi, H.J. and de Swaan, A. 1990. Vapor-liquid equilibrium for the system ammonia + water up to the critical region. J Chem Eng Data. Vol. 35: 140-144.

Scatchard, G., Epstein, L.F., Warburton, J. and Cody, P.J. 1947. Thermodynamic properties saturated liquid and vapor of ammonia-water mixtures, Refrigeration Engineering. Vol. 53: 413-452.

Smolen, T. M., Manley, D. B. and Poling, B.E. 1991. Vapor-liquid equilibrium data for the $\mathrm{NH}_{3}-\mathrm{H}_{2} \mathrm{O}$ system and its description with a modified cubic equation. J Chem Eng Data. Vol. 36: 202-208.

Taleb, A. H., Feidt, M. and Lottin, O. 2003. Thermodynamic properties of ammonia-water mixture. Proceedings, International Congress of Refrigeration, Washington D.C., ICR0113.

Tilner-Roth, R. and Friend, D.G. 1998. A Helmoltz free energy formulation of the thermodynamic properties of the mixture \{Ammonia+water\}. Journal of Physical Chemistry. Vol. 27(1): 63 - 96.

Weber, L.A. 1999. Estimating the virial coefficients of the ammonia-water mixture. Fluid Phase Equilibria. Vol. 162: 31-49.

Wilson, T.A. 1924. Properties of aqua-ammonia part 1. The total pressures. Refrigeration Engineering. Vol.10:248252.

$\mathrm{Xu}$, F. and Goswami, D. Y. 1999. Thermodynamic properties of ammonia water mixtures for use in power cycles. Energy. Vol. 24: 525-536.

$\mathrm{Xu}$, F.and Goswami, D. Y. 2002. Erratum to: thermodynamic properties of ammonia water mixtures for use in power cycles. Energy. Vol. 27: 203-203.

Ziegler, B. and Trepp, C. 1984. Equation of state for ammonia-water mixtures. International Journal of. Refrigeration. Vol.7:101-106. 